\title{
Critical Appraisal of Neuroprotection Trials in Head Injury: What Have We Learned?
}

\author{
Christos M. Tolias and M. Ross Bullock \\ Division of Neurosurgery, Medical College of Virginia, Virginia Commonwealth University, Richmond, Virginia $23298-0631$
}

Summary: To date, despite very encouraging preclinical results, almost all phase II/III clinical neuroprotection trials in traumatic brain injury (TBI) have failed to show any consistent improvement in outcome for TBI patients. To understand the reasons behind such developments we need to review and evaluate the evolution of trial design as a result of our changing understanding of the pathophysiology of brain cell death and progress of translational research from the laboratory bench to the bedside. This paper attempts to critically appraise these neuroprotection trials, rationalize the paucity of effectiveness, review any recent developments in the field, and try to draw some conclusions on how to move forward. Key Words: Head injury, trials, neuroprotection, translational research, trial design.

\section{INTRODUCTION}

Traumatic brain injury (TBI) remains a major health problem with serious socioeconomic consequences. Although its incidence is decreasing in most Western countries, ${ }^{1,2}$ according to some estimates, severe TBI will become the third most common cause of death and disability globally by the year $2020 .^{3}$

The initial injury, otherwise known as primary injury, has been traditionally considered as irreversible and only amenable to preventative measures like wearing seat belts, helmets, reducing vehicle speed limit, and other traffic improvements. Emerging evidence, however, has challenged this established concept. Primary injury is no longer seen as a single irreversible event occurring at the time of impact, but rather as a process (also known as "secondary brain injury") initiated by the impact and evolving over subsequent hours and days. Experimental work both, in vitro and in vivo has been slowly unraveling a cascade of interplaying mechanisms, which appear to be responsible for the continuing brain cell death following the primary impact of TBI.

The concept of "neuroprotection" is an expanding ar-

Address correspondence and reprint requests to M. Ross Bullock, M.D., Ph.D., Division of Neurosurgery, Medical College of Virginia, Virginia Commonwealth University, P.O. Box 980631, Richmond, VA 23298-0631. E-mail: robulloc@mail2.vcu.edu. ray of mainly pharmacological interventions that attempt to interrupt these processes and thus improve the outcome of TBI patients. To date, however, despite very encouraging preclinical results, almost all phase II/III clinical trials in neuroprotection have failed to show any consistent improvement in outcome for TBI patients. This paper attempts to critically appraise these neuroprotection trials, rationalize the paucity of effectiveness, review any recent developments in the field and try to draw some conclusions on how to move forward. An extensive review of the clinical trials in TBI has been published following the National Institute of Neurological Disorders and Stroke (NINDS) workshop in May $2000 .^{2}$

\section{HEAD INJURY TRIALS}

At least 20 compounds and therapeutic interventions have been subjected to more than 50 trials in the last three decades. The field has progressed steadily and lessons learned from previous failures were slowly incorporated in subsequent trials. In spite of showing improvement in some surrogate endpoints and strong indications that many of the trial compounds would have beneficial effects, none achieved consistent statistical significance in reducing adverse outcomes in the treatment groups following TBI. Moreover, many trials were halted by the pharmaceutical sponsors because of interim 
TABLE 1. Status of Recent Neuroprotection Clinical Trials in Traumatic Brain Injury, July 2003

\begin{tabular}{|c|c|c|c|}
\hline Agent/Interventiol & Type of Agent & Type of Studies & Outcome/Comments \\
\hline Selfotel & $\begin{array}{l}\text { Competitive NMDA } \\
\text { antagonist }\end{array}$ & 4 Phase III, DBPCRT & $\begin{array}{l}\text { Terminated because of high mortality in concomitant stroke } \\
\text { trials }\end{array}$ \\
\hline Cerestat & $\begin{array}{l}\text { Noncompetitive NMDA } \\
\text { antagonist }\end{array}$ & Phase III, DBPCRT & $\begin{array}{l}\text { Interim analysis showed no benefit; significant intercenter } \\
\text { variability }\end{array}$ \\
\hline Eliprodil & NR2B subunit antagonist & Phase II/III, DBPCRT & $\begin{array}{l}\text { Outcome better in "brain swelling subgroup" (2000); no new } \\
\text { information available }\end{array}$ \\
\hline CP 101-606 & $\begin{array}{l}\text { Second-generation NR2B } \\
\text { subunit antagonist }\end{array}$ & Phase II/III, DBPCRT & Data analysis awaiting publication \\
\hline D-CPP-ene & $\begin{array}{l}\text { Competitive NMDA } \\
\text { antagonist }\end{array}$ & Phase III, DBPCRT & $\begin{array}{l}\text { No benefit at } 6 \text { months; questions about appropriate dosing } \\
\text { regimen }\end{array}$ \\
\hline Steroids & $\begin{array}{l}\text { Lipid peroxidation inhibi- } \\
\text { tors }\end{array}$ & 14 Phase II/III trials & $\begin{array}{l}\text { No clear benefit, although metanalysis has suggested a possi- } \\
\text { ble small effect, not detectable by small numbers }{ }^{71}\end{array}$ \\
\hline Triamcinolone & Steroid & Phase III, DBPCRT & $\begin{array}{l}\text { Significant benefit in subgroup with a focal lesion and a GCS } \\
\text { on admission of }<8^{72}\end{array}$ \\
\hline $\begin{array}{l}\text { Tirilazad } \\
\text { mesylate }\end{array}$ & $\begin{array}{l}\text { Free radical scavenger } \\
\text { and lipid peroxidation } \\
\text { inhibitor }\end{array}$ & Phase III, DBPCRT & $\begin{array}{l}\text { May be effective in reducing mortality rates in males with } \\
\text { accompanying traumatic SAH; no significant differences in } \\
\text { frequency or types of serious adverse events }{ }^{73}\end{array}$ \\
\hline PEG-SOD & Free radical scavenger & Phase II/III, DBPCRT & Better outcome in patients who received $10000 \mathrm{U} / \mathrm{kg}$ \\
\hline Nimodipine & Calcium channel blocker & Phase II/III, DBPCRT & Significant improvement in the subgroup with traumatic $\mathrm{SAH}$ \\
\hline Bradycor & $\begin{array}{l}\text { Bradykinin receptor } \\
\text { antagonist }\end{array}$ & Phase II/III, DBPCRT & $\begin{array}{l}\text { Prematurely halted due to animal studies concerns; no signifi- } \\
\text { cant improvement in GOS at } 3 \text { and } 6 \text { months but reduction } \\
\text { of ICP achieved }{ }^{74}\end{array}$ \\
\hline $\begin{array}{l}\text { Ziconotide } \\
\qquad(\text { SNX-111) }\end{array}$ & $\begin{array}{l}\text { N-type voltage-sensitive } \\
\text { calcium channel blocker } \\
\text { (mitochondria) }\end{array}$ & Phase II/III, DBPCRT & Terminated due to increased mortality in the treatment group \\
\hline $\mathrm{ICP} / \mathrm{CBF}$ & $\begin{array}{l}\text { Study of CPP versus ICP- } \\
\text { centered TBI treatment }\end{array}$ & Prospective randomized & $\begin{array}{l}\text { No specific benefit of CPP protocol; increased respiratory } \\
\text { problems with CPP protocol } 76\end{array}$ \\
\hline Hypothermia & Moderate cooling $\left(33^{\circ} \mathrm{C}\right)$ & Phase III, DBPCRT & $\begin{array}{l}\text { Enrollment stopped due to futility analysis indicating very } \\
\text { low probability of detecting an effect }(<0.01 \%)^{64} \text {; ongoing } \\
\text { subgroup trial }\end{array}$ \\
\hline Progesterone & Hormone & Phase II DBPCRT & Ongoing \\
\hline $\begin{array}{l}\text { Magnesium } \\
\text { sulphate }\end{array}$ & $\begin{array}{l}\text { NMDA antagonist, cy- } \\
\text { toskeleton stabilizer }\end{array}$ & Phase III, DBPCRT & Ongoing \\
\hline Dexanabinol & $\begin{array}{l}\text { Marijuana derivative; } \\
\text { noncompetitive NMDA } \\
\text { antagonist, free radical } \\
\text { scavenger and TNF } \alpha \\
\text { inhibitor }\end{array}$ & $\begin{array}{l}\text { Phase II DBPCRT (tighter } \\
\text { inclusion criteria) }\end{array}$ & $\begin{array}{l}\text { No significant adverse outcome differences; ICP reduction was } \\
\text { achieved in treatment group and overall better performance in } \\
\text { surrogate endpoints }{ }^{75} \text {; a phase III trial is under way }\end{array}$ \\
\hline $\begin{array}{l}\text { Dexamethasone } \\
\text { (CRASH) }\end{array}$ & $\begin{array}{l}\text { Lipid peroxidation inhibi- } \\
\text { tor }\end{array}$ & Phase III, DBPCRT & $\begin{array}{l}\text { Ongoing; mainly dealing with moderate/mild TBI; enrollment of } \\
10000 \text { patients is planned ( } 4800 \text { patients enrolled to date) }\end{array}$ \\
\hline Topiramate & $\begin{array}{l}\text { AMPA/kainate receptor } \\
\text { inhibitor }\end{array}$ & Phase II study $(n=20)$ & $\begin{array}{l}\text { Mechanistic evidence of glutamate reduction and neurochemi- } \\
\text { cal "improvement" }\end{array}$ \\
\hline Cyclosporin A & $\begin{array}{l}\text { Mitochondrial transitional } \\
\text { pore (MPTP) formation } \\
\text { blocker }\end{array}$ & Phase II/III, DBPCRT & Ongoing \\
\hline
\end{tabular}

Adapted from Bullock et al. ${ }^{4}$ and Narayan et al. ${ }^{2}$

"futility analyses" and in some cases because of safety concerns. Table 1 summarizes the most important of these trials and gives an update on outcome and progress.

To understand the reasons that clinical trials in head injury have failed to show any significant improvement in outcome or in some cases even reached completion, we need to appreciate the following: 1) how our understanding of the pathophysiology of brain cell death has evolved, 2) how translational research progresses from the laboratory bench to the bedside, and 3) how trial design has evolved (specific selection criteria, statistical limitations, and outcome measures).

\section{PATHOPHYSIOLOGY OF BRAIN CELL DEATH}

TBI can cause both focal and diffuse damage to the brain. Ischemia, diffuse axonal injury, focal hematomas/ contusions, and edema contribute to a certain degree to the progressive loss of brain cells following TBI. ${ }^{4}$ The 
research process and methodology, which has led to our current understanding of the pathophysiology of human TBI, is vital in explaining the rationale behind neuroprotection trials and their success or failure.

\section{Excitotoxicity}

Almost two decades ago, in vitro studies and animal models of focal ischemia demonstrated that ischemia (oxygen and glucose deprivation) caused anaerobic metabolism with increased cell glycolysis, lactate production, membrane ionic homeostasis compromise, excitotoxic (mainly glutamate) release, cellular swelling, and massive intracellular calcium $\left(\mathrm{Ca}^{2+)}\right.$ influx. ${ }^{5,6}$ This in turn resulted in multiple intracellular pathway activation with free radical release and oxidative damage, ${ }^{7}$ caspase activation, ${ }^{8}$ poly(ADP-ribose) polymerase (PARP-1) activation, ${ }^{9-11}$ energy depletion, and neuronal cell death. Oxidative damage from free radicals resulted in lipid peroxidation and propagation of cell membrane damage and death. In these models, glutamate excitotoxicity through the NMDA receptor, free radical activity (mainly nitric oxide and superoxide), and intracellular $\mathrm{Ca}^{2+}$ were considered central in the pathophysiology of neuronal cell death ${ }^{12,13}$ and became the primary targets of pharmaceutical neuroprotective interventions. A multitude of glutamate receptor antagonists, free radical scavengers and lipid peroxidation inhibitors, and $\mathrm{Ca}^{2+}$ channel inhibitors (see Table 1) were developed and achieved spectacular neuroprotection under experimental (often with pre-treatment protocols) conditions. However, their clinical success was not as impressive.

\section{Brain edema}

Other mechanisms, such as the kallikrein-kinin system, were also implicated in microcirculation disturbances and brain edema formation following TBI. ${ }^{14-16}$ These data indicated that cerebral contusion damages the blood-brain barrier, resulting in increased uptake and activation of plasma kallikrein-kinin system, leading to the formation of brain edema, microcirculatory dysfunction, and further enhancement of blood-brain barrier permeability, together with focal and perifocal pathological brain damage. A clinical trial of a bradykinin antagonist has been performed ${ }^{17}$ (see Table 1$)$.

\section{Diffuse axonal injury}

Diffuse axonal injury (DAI), on the other hand, had been traditionally considered an acceleration-deceleration injury resulting in widespread neuronal damage: small petechial hemorrhages and brain edema, which could be seen on CT scan, and extensive cytoskeletal axonal damage, which could be seen in neuropathological studies. Initially considered as part of severe TBI, recent evidence has demonstrated that DAI is present with any type of brain injury, focal or otherwise, ${ }^{18}$ and that it can be detected in more than $90 \%$ of TBI cases. ${ }^{19}$
Today, it is well known that DAI is seen in the majority of patients who die after severe TBI (25\% to $30 \%$ ), as well as in those who survive in a persistent vegetative or severely disabled state ( $4 \%$ to $15 \%$ of cases, respectively). ${ }^{20}$ Axonal damage appears also to underlay the reticular formation disruption in the brain stem, which is thought to be responsible for the coma that follows severe TBI. ${ }^{21}$

The cytoskeletal damage of DAI was initially assumed to occur rapidly, due to transmission of shear forces throughout the brain. It is now becoming clear, however, that tearing of axons occurs rarely. ${ }^{22}$ On the contrary, a progressive disruption of the axonal membrane is the norm, not only in severe but also in moderate and mild TBI cases. ${ }^{23}$ Mitochondrial disruption may play a central role in this process. ${ }^{24}$ Very recent evidence, moreover, has indicated that axonal damage and degeneration are not always associated with neuronal death, as it was assumed up to now. It may be possible for neurons to survive such insults and even attempt to regenerate, providing a further chance of recovery or intervention. ${ }^{25}$

\section{Mitochondria}

Early reports of possible changes in mitochondria associated with brain injury appeared in the Russian and Japanese literature in the 1960 s. $^{26,27}$ In the late 70 s and 80 s, electron microscopy studies confirmed that mitochondrial swelling was an integral part of the subcellular changes following brain injury, ${ }^{28}$ and regional brain metabolite level alterations supported mitochondrial dysfunction in TBI. ${ }^{29}$ Since then it became progressively clear that disruption of mitochondrial function might play a central role in the pathophysiology of secondary TBI. Mitochondria may act as $\mathrm{Ca}^{2+}$ sinks that sequester $\mathrm{Ca}^{2+}$ to preserve low cytoplasmic $\mathrm{Ca}^{2+}$ concentrations. This $\mathrm{Ca}^{2+}$ load within mitochondria may cause colloid osmotic swelling and loss of function by $\mathrm{Ca}^{2+}$-induced opening of the permeability transition pore (mitochondrial permeability transition pore). Mitochondrial dysfunction can lead to energy depletion, free radical release, and further cell death pathway activation. ${ }^{30-33}$ Therapies targeting mitochondrial dysfunction have been developed and are being tried in severe head injury ${ }^{24,34-36}$ (see Table 1).

\section{Apoptosis}

A parallel mechanism of brain cell death that is also emerging as important in TBI is that of apoptosis. Early in vitro and in vivo experiments in ischemia demonstrated that neuronal cells under specific conditions of substrate deprivation could follow a preprogrammed pathway of controlled cell death known as apoptosis. ${ }^{37,38}$ In contrast to necrosis, cells that undergo apoptosis die without membrane rupture and as a result, elicit less inflammatory reactions. The mechanism is present physiologically to dispose of redundant cell populations, especially during development. Apoptosis was demon- 
strated in $\mathrm{TBI}^{39}$ and was quickly correlated with mitochondrial integrity and function. ${ }^{30}$ The emergence of the cysteine protease family, known as caspases, as important mediators of apoptosis and the demonstration of their role in TBI, ${ }^{8}$ along with the realization that release of cytochrome $c$ from mitochondria can lead to their activation, ${ }^{40,41}$ confirmed further the interrelationship of the various subcellular mechanisms of TBI ${ }^{42}$ No specific treatments targeting caspases and apoptosis have been developed as yet.

All therapies that, to date, have been developed and tried, targeted one specific component of the puzzle, which we very briefly reviewed above. In animal (mainly rodent) studies such a strategy showed clear improvement in outcome measures; this, however, was not repeated in human patients.

It is important to realize that in most clinical trials in severe TBI, the actual mechanism against which the compound was directed had not been demonstrated in human subjects before the commencement of the trial. What do we actually know, therefore, of the human TBI pathophysiology?

\section{HUMAN DATA}

Few experimental techniques are directly applicable to humans. The ones employed are mainly imaging and invasive neuromonitoring techniques, which can be used to a varied degree, both for research and clinical purposes. Intracranial pressure (ICP) monitoring, cerebral microdialysis, tissue oxygen monitoring $\left(\mathrm{PtiO}_{2}\right)$, and jugular bulb oxygen saturation monitoring are the main ones, which give us continuous tissue information on the alterations of the extracellular environment and the intracranial conditions. They are, however, dependent on position (microdialysis and tissue oxygen) and their interpretation is still controversial. Imaging techniques like magnetic resonance spectroscopy (MRS) and PET scanning, as well as histopathological postmortem studies, also provide exciting and invaluable information on metabolic alterations at cellular and subcellular level following TBI. They are non-invasive and can examine multiple brain areas, but their data are "snapshots" in time. Finally, biochemical methods of analysis have also provided important evidence by demonstrating byproducts of neurodegeneration processes in serum and cerebrospinal fluid (CSF).

With the use of these techniques we have been able to demonstrate 1) that glutamate and aspartate are greatly increased in the brain extracellular fluid of severe TBI patients (correlating with severity of injury and probe position), ${ }^{43-45}$ 2) that regional variations of metabolites can occur depending on the presence of focal contusions and ischemic changes, ${ }^{46} 3$ ) that free radicals might play a role in human TBI, ${ }^{47-49} 4$ ) that there is mitochondrial dysfunction following human $\mathrm{TBI},{ }^{34}$ and 5) that brain metabolic alterations are important in humans and correlate with reduced regional cerebral blood flow. ${ }^{50,51}$

Moreover, the human response to TBI is not as uniform as the experimental animal one. There is significant controversy currently on the optimal treatment protocol for cerebral perfusion pressure (CPP) following TBI. ${ }^{52}$ Traditionally, reductions in ICP both surgical and pharmacological, with avoidance of hypotension and secondary metabolic insults, were considered the main aim of treatment and were uniformly applied to TBI patients. More recent approaches, however, tend to stress the importance of individual variations in human TBI pathophysiology, as cerebral autoregulation and vascular reactivity are considered, ${ }^{53,54}$ or as the volume effects of increased blood-brain barrier permeability and the effects of various iatrogenic interventions are analyzed. ${ }^{55}$ No specific benefit has been demonstrated by any approach yet.

These findings indicate that our current understanding of human TBI is still limited. Understanding these mechanisms further and designing mechanism-driven trials, where therapies are targeted to patients with definitive evidence of a pathophysiological process as well as a process observed prior in animals, may result in more effective clinical treatments. We need, therefore, better translation of lab results to the bedside.

\section{TRANSLATION OF EXPERIMENTAL EVIDENCE TO BEDSIDE THERAPIES}

Human TBI has been modeled experimentally using various animal models. The rodent lateral-fluid-percussion injury model is the most frequently used worldwide, while rodent models of controlled cortical contusion or weight-drop have also been widely used. ${ }^{56}$ Moreover, in vitro studies and animal models of ischemic stroke have made important contributions to the design of these trials, as focal ischemia plays a significant role in the pathophysiology of TBI. ${ }^{56}$ None of these models, however, adequately represents the complete heterogeneity of clinical TBI. ${ }^{57}$ For example, out of 168 reports that were published in the Journal of Neurotrauma over 5 years (1996-2000), only 7\% included a secondary insult in the protocol, which was usually hypoxemia alone. ${ }^{57} \mathrm{In}$ addition, coma, a vital part of the clinical picture of severe TBI, has not been reproduced adequately to date in rodents. Only some large animal models had any success, ${ }^{21}$ but few large animal studies have specifically addressed the mechanisms of neuronal damage and only rodent studies offer a well-validated and reproducible tool with established outcome measures to explore such inherently complicated processes.

Preclinical animal studies in TBI demonstrated impressive improvements in both histopathological and 
outcome endpoints with all the agents that progressed to clinical trials. However, these data were derived from pretreatment or ultra-early treatment protocols, when became increasingly clear that several hours after the injury, complex metabolic and biochemical changes can take place. Moreover, it is possible that by inhibiting one pathway of cell death, another one is up-regulated, probably in a delayed manner. Most of the animal models in use are not designed to detect such delayed changes or responses. ${ }^{58}$ In the preclinical stage of development Cerestat, for example, was never tested later than $15 \mathrm{~min}$ post-insult in the animal model. Direct extrapolation of the animal models to humans will always be problematic, as it is possible that the responses and therapeutic windows may be different. ${ }^{2,4}$ This might explain not only the lack of efficacy but also the unexpected toxicity encountered in some trials (Selfotel, Cerestat, hypothermia). Prolonged inhibition of NMDA receptors, cytokines, and temperature might result in inhibition of the normal regenerative processes that will ultimately effect brain recovery.

Another potential problem has been that the animals used were highly inbred adult rodent strains of a single sex (male). Although important for reproducibility and consistency of results, these experimental models might introduce unknown biases to the observed responses. Recent studies are attempting to introduce sex and age variables in the experimental paradigms with interesting results. The well-known variability in female responses to brain trauma, with female animals exhibiting smaller lesion volumes and consequently better outcome, ${ }^{59}$ was not confirmed in a recent prospective cohort from the tirilazad trial, where premenopausal women were significantly more likely to experience brain swelling and intracranial hypertension than male patients with a comparable injury severity. ${ }^{60}$

It is clear, therefore, that translation of experimental results needs to be improved. One way forward might be to expand the experimental protocols to outbred strains and to introduce more clinical variables to the experimental design. We may need to try potential agents in multiple models of TBI, SAH, and ischemia, to simulate more closely the real clinical picture. Targeting multiple components of the secondary cascade and altering the therapeutic window may also provide potential effective alternatives. $^{4,58}$

Moreover, tolerability and safety concerns need to be reviewed and adjusted. Many trials have been halted by the pharmaceutical sponsors because of concerns of behavioral and psychomimetic effects ${ }^{4}$ (see also Table 1). These events may not be as important in fully sedated, paralyzed, and ventilation-supported patients, where administration of the therapeutic agent is only short-term. Indeed, such toxicity testing is not required for chemo- therapy compounds directed at other high-mortality diseases like cancer.

Proper brain penetration of the trial medications also needs to be demonstrated in humans, especially in the presence of decreased cerebral perfusion pressure. No trial performed to date actually demonstrated human brain penetration and activity. Microdialysis is the only technique available that can be used in the early phase of clinical trials to establish brain penetration of the compound under investigation and also to demonstrate biological marker improvement. Use of microdialysis in a phase II trial of Topiramate in severe TBI demonstrated different free-drug concentrations in the extracellular space from that measured in CSF, the traditional method of establishing brain penetration, while indicating biochemical marker improvement correlating with dosing. ${ }^{61}$ Similar methodology in an on-going cyclosporin A study is helping to establish human brain pharmacokinetics and has demonstrated that free-drug concentrations in the human brain probably do not mirror those in plasma (unpublished observations). Further advances in microdialysis monitoring with "online," real-time measurements may allow such techniques to provide not only feedback for monitoring therapeutic drug dosing, but also possibly define the therapeutic window in individual patients.

Designing the human trial is obviously crucial in the success of any novel therapeutic intervention. The experimental protocol must take into consideration not only the laboratory results but should try to incorporate clinical parameters and variables as well. The aim is to encompass the spectrum of the disease or equally to limit the target population according to the mechanism under investigation/treatment. This brings us to trial design with the inevitable intercenter variability, statistical problems, and outcome measure sensitivity.

\section{TRIAL DESIGN (STATISTICAL PARAMETERS, INTERCENTER VARIABILITY, AND OUTCOME MEASURE SENSITIVITY)}

All the clinical trials performed to date followed an established pattern of preclinical development, safety stage, and outcome stage. After the toxicity studies in healthy animals and human volunteers, phase two studies were performed to be followed quickly and sometimes in combination by randomized, double-blind, multicenter trials. Such an approach had been tried in multiple pharmaceutical interventions in the past. Specific inclusion/ exclusion criteria were devised and enforced and recommendations for basic care management and care were suggested to minimize treatment variability. Multiple center involvement was deemed necessary to ensure results could be generalized; however, in the case of head injury, significant problems emerged. 
The main problems that many reviews identified in the trial design were 1) population selection (i.e., inclusion criteria and population size), 2)standardization of treatment and center monitoring, and 3) outcome endpoints.

\section{Population selection}

The progression from animal to human studies has been criticized as over-hurried and possibly over-ambitious. Treatment paradigms from animal models predicted improvements of outcome in excess of $10 \%$ and most trials were designed to demonstrate such an effect and were, as a result, grossly underpowered. ${ }^{2}$ Dickinson et al. ${ }^{62}$ demonstrated that out of 203 TBI trials none was large enough to reliably detect a 5\% absolute reduction in the risk of death or disability, and only eight were large enough to detect an absolute reduction of $10 \%$. Thus it is possible that a type 2 error might have doomed trials that could otherwise have demonstrated a beneficial effect.

One solution that has been proposed if the expected outcome difference is small is that of a "mega-trial" to include a sufficient number of patients and thus have enough statistical power to detect it. Based on such thinking, the CRASH (Corticosteroid Randomization after Significant Head Injury) trial is attempting to enroll 10,000 patients with mainly moderate and mild head injury (60\% of the total up to now) and expects to detect a reduction in mortality by $2 \% .{ }^{63}$ Of course, mortality will come mainly from severe head injury and thus the study may ultimately be unable to demonstrate any significant difference.

Better understanding of the pathophysiology at the preclinical stage should also assist in design, because the expected outcome improvement would be modified accordingly. It has become clear to all investigators that treatment of TBI is very diverse and controversial subject. Attempting to extract small changes in outcome from such a diverse field is probably impossible.

\section{Standardization of treatment}

Experience with large multinational, multicenter trials has clearly demonstrated that the heterogeneity of the condition and the population, as well as significant differences in admission policies, population coverage, age and injury mix, and treatment protocols, resulted in significant intercenter variability, which was not corrected by statistical methods. These differences were more evident between continents, but were also between centers in the same country. ${ }^{64,65}$ As a solution to this problem suggestions have been made of pre-randomization stratification by prognostic risk to increase the statistical power of the study by grouping patients with the highest likelihood of a large response. Such a maneuver would probably be impractical in the emergency setting of TBI. Incorporating statistical methods of covariate adjustment is a more feasible approach that might smooth out differences in the research populations. ${ }^{65}$

Protocol compliance and center variability has also been recognized as a major problem in international trials. In the hypothermia study only five centers (out of a total of eleven) randomized $88 \%$ of the patients. ${ }^{66}$ The suggestion to standardize treatment has been made by proposing strict management protocol of CPP, mean arterial pressure and fluid balance, and by closely monitoring protocol adherence and center activity. However, concerns about ability to generalize results, if such an approach is adopted, have also been expressed. ${ }^{67}$

\section{Outcome endpoints}

The most widely used outcome measure in TBI trials is the Glasgow Outcome Scale (GOS). It is frequently used as the "dichotomized GOS" of "good" and "bad" outcome. As such the five-point GOS becomes a two-point outcome measure with reduced sensitivity. Although it retains the advantage of discriminating between two clinically, socially, and economically meaningful states, ${ }^{68}$ it may not detect subtle improvements in patient outcome. If laboratory injury models were restricted to outcome measures with the same degree of sensitivity as the dichotomized GOS, there would be fewer candidate therapies for clinical trials. Outcome measures such as the Disability Rating Scale or the American Brain Injury Consortium Neuropsychological Test Battery may offer better sensitivity, but suffer from administrative difficulties and inter-observer variability. Ultimately, however, they analyze only a subcategory of patients that are neither severely disabled nor dead. It has been argued that in effect they do not offer any significant advantage over the dichotomized GOS. ${ }^{68}$

It is clear that, following TBI, improvements in functional outcome may occur, but it remains doubtful that they will become significant enough to demonstrate efficacy. Overall improvement in mortality and reduction in disability are probably the only primary endpoints that can be robust, reliable, and meaningful. This becomes even more difficult in an era of substantial "spontaneous" improvement of head injury outcome. It is important to realize, moreover, that these improvements have been demonstrated mainly in severe head injury. There is a lack of data for moderate and mild head injury, which constitute the majority of head injuries worldwide. Outcome measures for these injuries are, however, much more difficult to obtain.

Surrogate endpoints may, therefore, offer a solution and allow progress in the field. There has been an array of such endpoints, mainly ICP, biochemical markers, and imaging indices. The U.S. Food and Drug Administration has accepted surrogate endpoints as evidence of efficacy only when there was overwhelming data to correlate a surrogate endpoint with outcome (like choles- 
TABLE 2. Novel Neuroprotective Agents under Development, July 2003

\begin{tabular}{|c|c|c|c|}
\hline Agent & Type of Agent & Type of Studies & Comments \\
\hline BAY $38-7271$ & Cannabinoid agonist & Phase I & $\begin{array}{l}\text { Demonstrated highly potent and efficient neuroprotective } \\
\text { properties when administered immediately after induc- } \\
\text { tion of subdural hematoma ( } 70 \% \text { infarct volume reduc- } \\
\text { tion); even when applied with a } 3 \text {-h delay, a significant } \\
\text { neuroprotective efficacy could be observed (59\% infarct } \\
\text { volume reduction) })^{77}\end{array}$ \\
\hline NS 1209 & AMPA antagonist & Phase I & No data available \\
\hline S-1746 & AMPA antagonist & Phase I & No data available \\
\hline ARR-15896AR & NMDA antagonist & Preclinical & No data available \\
\hline BAY 44-2041 & $\begin{array}{l}\text { Adenosine re-uptake } \\
\text { inhibitor }\end{array}$ & Preclinical & Increases perfusion in $\mathrm{TBI}$; no data available \\
\hline Immunophilins & Immunosupressants & Prerclinical & Neuroprotectant properties in $\mathrm{TBI}^{78}$ \\
\hline $\begin{array}{l}\text { NAALADase } \\
\text { inhibitors }\end{array}$ & $\begin{array}{l}\text { NAALADase } \\
\text { inhibitors }\end{array}$ & Preclinical & Neuroprotectant properties in ischemia, $\mathrm{TBI}^{79}$ \\
\hline
\end{tabular}

terol in heart disease or CD4 count in acquired immune deficiency syndrome). Unfortunately, no such correlation has been demonstrated to date in head injury. The most investigated surrogate marker, ICP, has not been shown to correlate reliably with outcome. Serum and CSF concentrations of $\mathrm{S} 100 \mathrm{~B}$ have also been correlated with outcome (both functional and morphological) in severe and moderate head injury by many research groups, ${ }^{69}$ but significant doubts still remain on the actual tissue source of this protein under trauma conditions and its physiologic significance. ${ }^{69,70}$

\section{THERAPIES IN DEVELOPMENT}

Apart from the trials described above (Table 1), a number of pharmaceutical compounds are currently in the early stages of development (Table 2). It remains to be seen which, if any, of these compounds will succeed in the path of improving outcome after human TBI.

\section{CONCLUSIONS}

The ideal trial in head injury is not possible. Specific lessons, however, have been learned from previous attempts and general principles can be suggested: 1) better understanding of the pathophysiology of head injury both severe and moderate is imperative, and the mechanism should be demonstrated in both animal models and human TBI; 2) better translational processes are very important to design therapeutic interventions that have relevance to the clinical practice, brain tissue penetration and pharmacokinetics in human TBI should be carefully considered and investigated, safety data should include interactions with other agents, and the possibility of multiple agent treatment should be explored; 3) the appropriate therapeutic time-window should be identified and dynamic processes should be developed to allow individual patient adjustments, e.g., giving the trial medication at the site of the accident; 4) as a result of the above, specific consideration of the actual consent procedure and serious thought should be given to the concept of waived consent for trials in head injury; 5) proper patient selection is necessary, which will expose to treatment those patients that will benefit most from any potential intervention; 6) identification of an appropriate surrogate endpoint is highly desirable, but it has to be fully validated before it can be applied; 7) careful statistical evaluation before and during any trial will ensure avoidance of pitfalls in recruitment and analysis; protocol adherence and center monitoring is important in establishing internal validity and smoothing out the significant variability in treatment, and 8) full publication of the results of any trial, irrespective of the outcome, is imperative for all investigators to scrutinize the data and draw appropriate conclusions as early as possible. ${ }^{71-79}$

\section{REFERENCES}

1. Kay A, Teasdale GM. Head injury in the United Kingdom. World J Surg 25:1210-1220, 2001.

2. Narayan RK, Michael ME, The Clinical Trials in Head Injury Study Group. Clinical trials in head injury. J Neurotrauma 19:503557, 2002.

3. Murray CJL, Lopez AD. Global mortality, disability and the contribution of the risk factors: global burden of disease study. Lancet 349:1436-1442, 1997.

4. Bullock R, Lyeth BG, Muizelaar JP. Current status of neuroprotection trials for traumatic brain injury: lessons from animal models and clinical studies. Neurosurgery 45:207-220, 1999.

5. Choi DW, Maulucci-Gedde M, Kriegstein AR. Glutamate neurotoxicity in cortical cell culture. J Neurosci 7:357-368, 1987.

6. Faden AI, Demediuk P, Panter SS, Vink R. The role of excitatory amino acids and NMDA receptors in traumatic brain injury. Science 244:798-800, 1989.

7. Bredt DS, Snyder SH. Nitric oxide mediates glutamate-linked enhancement of cGMP levels in the cerebellum. Proc Natl Acad Sci USA 86:9030-9033, 1989. 
8. Yakovlev AG, Knoblach SM, Fan L, Fox GB, Goodnight R, Faden AI. Activation of CPP32-like caspases contributes to neuronal apoptosis and neurological dysfunction after traumatic brain injury. J Neurosci 17:7415-7424, 1997.

9. Zhang J, Dawson VL, Dawson TM, Snyder SH. Nitric oxide activation of poly(ADP-ribose) synthetase in neurotoxicity. Science 263:687-689, 1994.

10. Ha HC, Snyder SH. Poly(ADP-ribose) polymerase is a mediator of necrotic cell death by ATP depletion. Proc Natl Acad Sci USA 96:13978-13982, 1999.

11. Mandir AS, Poitras MF, Berliner AR, Herring WJ, Guastella DB, Feldman A et al. NMDA but not non-NMDA excitotoxicity is mediated by Poly(ADP-ribose) polymerase. J Neurosci 20:80058011,2000

12. Bullock R, Kuroda Y, Teasdale GM, McCulloch J. Prevention of post-traumatic excitotoxic brain damage with NMDA antagonist drugs: a new strategy for the nineties. Acta Neurochir Suppl (Wien) 55:49-55, 1992.

13. Choi DW. Calcium and excitotoxic neuronal injury. Ann NY Acad Sci 747:162-171, 1994.

14. Unterberg A, Baethmann AJ. The kallikrein-kinin system as mediator in vasogenic brain edema. Part 1: cerebral exposure to bradykinin and plasma. J Neurosurg 61:87-96, 1984.

15. Maier-Hauff K, Baethmann AJ, Lange M, Schurer L, Unterberg A. The kallikrein-kinin system as mediator in vasogenic brain edema. Part 2: studies on kinin formation in focal and perifocal brain tissue. J Neurosurg 61:97-106, 1984.

16. Unterberg A, Dautermann C, Baethmann A, Muller-Esterl W. The kallikrein-kinin system as mediator in vasogenic brain edema. Part 3: inhibition of the kallikrein-kinin system in traumatic brain swelling. J Neurosurg 64:269-276, 1986.

17. Marmarou A, Nichols J, Burgess J, Newell D, Troha J, Burnham D, Pitts L. Effects of the bradykinin antagonist Bradycor (deltibant, CP-1027) in severe traumatic brain injury: results of a multi-center, randomized, placebo-controlled trial. American Brain Injury Consortium Study Group. J Neurotrauma 16:431-444, 1999.

18. Sahuquillo-Barris J, Lamarca-Ciuro J, Vilalta-Castan J, RubioGarcia E, Rodriguez-Pazos M. Acute subdural hematoma and diffuse axonal injury after severe head trauma. J Neurosurg 68:894900, 1988.

19. Gentleman SM, Roberts GW, Gennarelli TA, Maxwell WL, Adams JH, Kerr S et al. Axonal injury: a universal consequence of fatal closed head injury? Acta Neuropathol (Berl) 89:537-543, 1995.

20. Reinert MM, Bullock R. Clinical trials in head injury. Neurol Res 21:330-338, 1999.

21. Smith DH, Nonaka M, Miller R, Leoni M, Chen XH, Alsop D et al. Immediate coma following inertial brain injury dependent on axonal damage in the brainstem. J Neurosurg 93:315-322, 2000.

22. Maxwell WL, Povlishock JT, Graham DL. A mechanistic analysis of nondisruptive axonal injury: a review. J Neurotrauma 14:419440, 1997.

23. Pettus EH, Christman CW, Giebel ML, Povlishock JT. Traumatically induced altered membrane permeability: its relationship to traumatically induced reactive axonal change. J Neurotrauma 11: 507-522, 1994.

24. Okonkwo DO, Povlishock JT. An intrathecal bolus of cyclosporin A before injury preserves mitochondrial integrity and attenuates axonal disruption in traumatic brain injury. J Cereb Blood Flow Metab 19:443-451, 1999.

25. Lifshitz J, Friberg H, Neumar RW, Raghupathi R, Welsh FA, Janmey $\mathrm{P}$ et al. Structural and functional damage sustained by mitochondria after traumatic brain injury in the rat: evidence for differentially sensitive populations in the cortex and hippocampus. $J$ Cereb Blood Flow Metab 23:219-231, 2003.

26. Tigranian RA, Promyslov MS. Peculiarities of oxidative phosphorylation in brain mitochondria with craniocerebral trauma. Ukr Biokhim Zh 41:170-173, 1969.

27. Arai C, Ozawa K. Studies on the biochemical aspects of brain injuries and brain edema with special reference to functional changes of mitochondria in the brain. Shinkei Kenkyu No Shimpo 9:611-622, 1965.

28. Bakay L, Lee JC, Lee GC, Peng JR. Experimental cerebral con- cussion. Part 1: an electron microscopic study. J Neurosurg 47: 525-531, 1977.

29. Yang MS, DeWitt DS, Becker DP, Hayes RL. Regional brain metabolite levels following mild experimental head injury in the cat. J Neurosurg 63:617-621, 1985.

30. Ankarcrona M, Dypbukt JM, Bonfoco E, Zhivotovsky B, Orrenius S, Lipton SA, Nicotera P. Glutamate-induced neuronal death: a succession of necrosis or apoptosis depending on mitochondrial function. Neuron 15:961-973, 1995.

31. Uchino H, Elmer E, Uchino K, Lindvall O, Siesjo BK. Cyclosporin A dramatically ameliorates CA1 hippocampal damage following transient forebrain ischemia in the rat. Acta Physiol Scand 155: 469-471, 1995.

32. Xiong Y, Gu Q, Peterson PL, Muizelaar JP, Lee CP. Mitochondrial dysfunction and calcium perturbation induced by traumatic brain injury. J Neurotrauma 14:23-34, 1997.

33. Clausen T, Zauner A, Levasseur JE, Rice AC, Bullock R. Induced mitochondrial failure in the feline brain: implications for understanding acute post-traumatic metabolic events. Brain Res 908:3548, 2001.

34. Verweij BH, Muizelaar JP, Vinas FC, Peterson PL, Xiong Y, Lee CP. Mitochondrial dysfunction after experimental and human brain injury and its possible reversal with a selective N-type calcium channel antagonist (SNX-111). Neurol Res 19:334-339, 1997.

35. Buki A, Okonkwo DO, Povlishock JT. Postinjury cyclosporin A administration limits axonal damage and disconnection in traumatic brain injury. $J$ Neurotrauma 16:511-521, 1999.

36. Alessandri B, Rice AC, Levasseur J, DeFord M, Hamm RJ, Bullock MR. Cyclosporin A improves brain tissue oxygen consumption and learning/memory performance after lateral fluid percussion injury in rats. J Neurotrauma 19:829-841, 2002.

37. MacManus JP, Buchan AM, Hill IE, Rasquinha I, Preston E. Global ischemia can cause DNA fragmentation indicative of apoptosis in rat brain. Neurosci Lett 164:89-92, 1993.

38. Beilharz EJ, Williams CE, Dragunow M, Sirimanne ES, Gluckman PD. Mechanisms of delayed cell death following hypoxic-ischemic injury in the immature rat: evidence for apoptosis during selective neuronal loss. Brain Res Mol Brain Res 29:1-14, 1995.

39. Rink A, Fung KM, Trojanowski JQ, Lee VM, Neugebauer E, McIntosh TK. Evidence of apoptotic cell death after experimental traumatic brain injury in the rat. Am J Pathol 147:1575-1583, 1995.

40. Buki A, Okonkwo DO, Wang KK, Povlishock JT. Cytochrome c release and caspase activation in traumatic axonal injury. $J \mathrm{Neu}$ rosci 20:2825-2834, 2000.

41. Sullivan PG, Keller JN, Bussen WL, Scheff SW. Cytochrome c release and caspase activation after traumatic brain injury. Brain Res 949:88-96, 2002.

42. Yakovlev AG, Faden AI. Caspase-dependent apoptotic pathways in CNS injury. Mol Neurobiol 24:131-144, 2001.

43. Bullock R, Zauner A, Myseros JS, Marmarou A, Woodward JJ, Young HF. Evidence for prolonged release of excitatory amino acids in severe human head trauma. Relationship to clinical events. Ann NY Acad Sci 765:290-297, 1995.

44. Gopinath SP, Valadka AB, Goodman JC, Robertson CS. Extracellular glutamate and aspartate in head injured patients. Acta Neurochir Suppl 76:437-438, 2000.

45. Tolias CM, Richards DA, Bowery NG, Sgouros S. Extracellular glutamate in the brains of children with severe head injuries: a pilot microdialysis study. Childs Nerv Syst 18:368-374, 2002.

46. Sarrafzadeh AS, Sakowitz OW, Callsen TA, Lanksch WR, Unterberg AW. Detection of secondary insults by brain tissue pO2 and bedside microdialysis in severe head injury. Acta Neurochir Suppl 81:319-321, 2002.

47. Khaldi A, Chiueh CC, Bullock MR, Woodward JJ. The significance of nitric oxide production in the brain after injury. Ann NY Acad Sci 962:53-59, 2002.

48. Silberstein M, Lane D, Dodd S, Opeskin K. Identification of a by-product of nitric oxide synthase activity in human acute brain injury with in vivo proton magnetic resonance spectroscopy. Am J Neuroradiol 23:389-392, 2002.

49. Kasprzak HA, Wozniak A, Drewa G, Wozniak B. Enhanced lipid 
peroxidation processes in patients after brain contusion. $J$ Neurotrauma 18:793-797, 2001.

50. Reinert M, Hoelper B, Doppenberg E, Zauner A, Bullock R. Substrate delivery and ionic balance disturbance after severe human head injury. Acta Neurochir Suppl 76:439-444, 2000.

51. Hutchinson PJ, Gupta AK, Fryer TF, Al-Rawi PG, Chatfield DA, Coles JP et al. Correlation between cerebral blood flow, substrate delivery, and metabolism in head injury: a combined microdialysis and triple oxygen positron emission tomography study. J Cereb Blood Flow Metab 22:735-745, 2002.

52. Robertson CS. Management of cerebral perfusion pressure after traumatic brain injury. Anesthesiology 95:1513-1517, 2001.

53. Steiner LA, Czosnyka M, Piechnik SK, Smielewski P, Chatfield D, Menon DK et al. Continuous monitoring of cerebrovascular pressure reactivity allows determination of optimal cerebral perfusion pressure in patients with traumatic brain injury. Crit Care Med 30:733-738, 2002.

54. Czosnyka M, Smielewski P, Piechnik S, Steiner LA, Pickard JD. Cerebral autoregulation following head injury. J Neurosurg 95: 756-763, 2001

55. Eker C, Asgeirsson B, Grande PO, Schalen W, Nordstrom CH. Improved outcome after severe head injury with a new therapy based on principles for brain volume regulation and preserved microcirculation. Crit Care Med 26:1881-1886, 1998.

56. Povlishock JT, Hayes RL, Michel ME, McIntosh TK. Workshop on animal models of traumatic brain injury. $J$ Neurotrauma 11: 723-732, 1994.

57. Statler KD, Jenkins LW, Dixon CE, Claek RS, Marion DW, Kochanek PM. The simple model versus the super model: translating experimental traumatic brain injury research to the bedside. J Neurotrauma 18:1195-1206, 2001.

58. Faden AI. Neuroprotection and traumatic brain injury: theoretical option or realistic proposition. Curr Opin Neurol 15:707-712, 2002.

59. Bramlett HM, Dietrich WD. Neuropathological protection after traumatic brain injury in intact female rats versus males or ovariectomized females. J Neurotrauma 18:891-900, 2001.

60. Farin A, Deutsch R, Biegon A, Marshall LF. Sex-related differences in patients with severe head injury: greater susceptibility to brain swelling in female patients 50 years of age and younger. J Neurosurg 98:32-36, 2003.

61. Alves OL, Doyle A, Gilman C, Sarkar M, Young HF, Bullock R. Evaluation of topiramate neuroprotective effect in severe TBI by using microdialysis. Abstract of oral presentation at AANS Meeting, San Diego, 2003. J Neurosurg 98:712, 2003.

62. Dickinson K, Bunn F, Wentz R, Edwards P, Roberts I. Size and quality of randomized controlled trials in head injury: review of published studies. Br Med J 320:1308-1311, 2000.

63. MRC CRASH Trial National Coordinators. Update on progress in the international multicenter, randomized, controlled trial of corticosteroids after significant head injury (Medical Research Council CRASH Trial). Curr Opin Crit Care 9:92-97, 2003.

64. Clifton GL, Miller ER, Choi SC, Levin HS, McCauley S, Smith KR Jr et al. Lack of effect of induction of hypothermia after acute brain injury. N Engl J Med 344:556-563, 2001.
65. Hukkelhoven CW, Steyerberg EW, Farace E, Habbema JD, Marshall LF, Maas AI. Regional differences in patient characteristics, case management, and outcomes in traumatic brain injury: experience from the tirilazad trials. J Neurosurg 97:549-557, 2002.

66. Clifton GL, Choi SC, Miller ER, Levin HS, Smith KR Jr, Muizelaar JP et al. Intercenter variance in clinical trials of head traumaexperience of the National Acute Brain Injury Study: Hypothermia. J Neurosurg 95:751-755, 2001.

67. Marshall LF. Intercenter variance. J Neurosurg 95:733-734, 2001.

68. Teasdale GM. Comment on Bullock R, Lyeth BG, Muizelaar JP. Current status of neuroprotection trials for traumatic brain injury: lessons from animal models and clinical studies. Neurosurgery 45:207-220, 1999.

69. Rothermundt M, Peters M, Prehn JH, Arolt V. S100B in brain damage and neurodegeneration. Mic Res Tech 60:614-632, 2003.

70. Anderson RE, Hansson LO, Nilsson O, Liska J, Settegren G. High serum S100B levels for trauma patients without head injuries. Neurosurgery 48:1255-1260, 2001.

71. Alderson P, Roberts I. Corticosteroids in acute traumatic brain injury: systematic review of randomized controlled trials. $\mathrm{Br}$ Med J 314:1855-1859, 1997.

72. Grumme T, Baethmann A, Kolodziejczyk D, Krimmer J, Fischer M, von Eisenhart Rothe B et al. Treatment of patients with severe head injury by triamcinolone: a prospective, controlled multicenter clinical trial of 396 cases. Res Exp Med (Berl) 195:217-229, 1995.

73. Marshall LF, Maas AI, Marshall SB, Bricolo A, Fearnside M, Iannotti $\mathrm{F}$ et al. A multicenter trial on the efficacy of using tirilazad mesylate in cases of head injury. J Neurosurg 89:519-525, 1998.

74. Marmarou A, Nichols J, Burgess J, Newell D, Troha J, Burnham D, Pitts L. Effects of the bradykinin antagonist Bradycor (deltibant, CP-1027) in severe traumatic brain injury: results of a multi-center, randomized, placebo-controlled trial. American Brain Injury Consortium Study Group. J Neurotrauma 16:431-444, 1999.

75. Knoller N, Levi L, Shoshan I, Reichenthal E, Razon N, Rappaport $\mathrm{ZH}$ et al. Dexanabinol (HU-211) in the treatment of severe closed head injury: a randomized, placebo-controlled, phase II clinical trial. Crit Care Med 30:548-554, 2002.

76. Robertson CS, Valadka AB, Hannay HJ, Contant CF, Gopinath SP, Cormio $\mathrm{M}$ et al. Prevention of secondary ischemic insults after severe head injury. Crit Care Med 27:2086-2095, 1999.

77. Mauler F, Mittendorf J, Horvath E, De Vry J. Characterization of the diarylether sulfonylester (-)-(R)-3-(2-hydroxymethylindanyl-4oxy)phenyl-4,4,4-trifluoro-1-sulfonate (BAY $38-7271$ ) as a potent cannabinoid receptor agonist with neuroprotective properties. J Pharmacol Exp Ther 302:359-368, 2002.

78. Fumoto N, Nakatsuka H, Ohta S, Kumon Y, Ohnishi T. Hippocampal CA1 neuron survival and cytosolic FKBP12, the $12 \mathrm{kDa}$ FK506-binding protein, after ischemia and tacrolimus treatment in gerbils. Neurosci Lett 339:219-222, 2003.

79. Jackson PF, Tays KL, Maclin KM, Ko YS, Li W, Vitharana D et al. Design and pharmacological activity of phosphinic acid based NAALADase inhibitors. $J$ Med Chem 44:4170-4175, 2001. 